\title{
Nursing student's perceptions of learning in practice environments: A review
}

\section{Authors:}

Amanda Henderson

$\mathrm{PhD}, \mathrm{RN}$

Professor, Director of Nursing Education

Nursing Practice Development Unit, Princess Alexandra Hospital,

Research Centre for Clinical \& Community Practice Innovation

Griffith Institute of Health and Medical Research

Griffith University, Nathan, 4111, Queensland Australia

amanda henderson@health.qld.gov.au

Tel: (07) 31762780

Fax: (07) 31767356

Marie Cooke

PhD, MSPD, BAppSc, DAppSc (Nurs\&UnitMgt), RN

Professor, Deputy Head of School, School of Nursing and Midwifery,

Research Centre for Clinical \& Community Practice Innovation

Griffith Institute of Health and Medical Research

Griffith University, Nathan, 4111, Queensland Australia

Debra K. Creedy

PhD, M Ed, BA (Hons), RN

Professor, Head of Alice Lee Centre for Nursing Studies,

Yong Loo Lin School of Medicine at National University of Singapore

Research Centre for Clinical and Community Practice Innovation at Griffith University, Nathan, 4111, Queensland Australia

Rachel Walker

$\mathrm{MN}, \mathrm{BN}, \mathrm{BA}, \mathrm{RN}$

Lecturer, Clinical Coordinator, School of Nursing and Midwifery

Research Centre for Clinical \& Community Practice Innovation

Griffith Institute of Health and Medical Research

Griffith University, Nathan, 4111, Queensland Australia 


\section{Abstract}

Effective clinical learning requires integration of nursing students into ward activities, staff engagement to address individual student learning needs, and innovative teaching approaches. Assessing characteristics of practice environments can provide useful insights for development.

This study identified predominant features of clinical learning environments from nursing students' perspectives across studies using the same measure in different countries over the last decade. Six studies, from three different countries, using the Clinical Leaning Environment Inventory (CLEI) were reviewed. Studies explored consistent trends about learning environment. Students rated sense of task accomplishment high. Affiliation also rated highly though was influenced by models of care. Feedback measuring whether students' individual needs and views were accommodated consistently rated lower. Across different countries students report similar perceptions about learning environments. Clinical learning environments are most effective in promoting safe practice and are inclusive of student learners, but not readily open to innovation and challenges to routine practices.

\section{Key words}

Student nurses, learning environment, affiliation, task orientation

\section{What is known}

- Clinical nursing education is historically ritualistic

- Contemporary education aims to foster students' abilities to question practice and seek evidence around health care practice

- A welcoming clinical practice environment is instrumental to learning

- Positive learning environments that facilitate students to engage in practice are pivotal if nursing is to shift from traditional routine base to practice based on evidence 


\section{What is this paper adds}

- Didactic teaching of skills and practices still dominant learning environments

- Students report that they largely affiliate with the team, that is, they 'fit in'

- Students are not actively engaged to question the effectiveness of existing practices

- Students perceive that learning environments are not conducive to initiating innovation

\section{Introduction}

Contemporary health care occurs within a dynamic knowledge environment that requires clinicians to be well educated, life-long learners, and engaged with research evidence underpinning practice. The complexity of knowledge required for efficient and effective patient care needs to be open to scrutiny to better inform practice. For these reasons the education of health professionals, in particular nurses, has shifted from an apprentice-based training model where the routine practice of tasks and activities are emphasised, to a university-based preparation that educates students to understand situations and seek and judiciously use evidence in practice.

In health professional education the clinical context is recognised as an essential arena for students to learn about practice in the 'real' world (Egan and Jaye, 2009). The clinical practicum is a large and important component of any undergraduate nursing degree. Experiences within clinical contexts are powerful in shaping student attitudes to learning, practice and professional development. The literature repeatedly identifies the importance of the immediate environment in how and what students learn (Clarke et al., 2003; Papp et al., 2003). This paper reviews students' perceptions of the practice environment from quantitative studies using the same outcome measure (Clinical Learning Environment Inventory [CLEI]) (Chan 2001, 2002, 2003), that shape how and what nurses learn, drawing implications for how students learn to apply knowledge to practice situations. 
An exploration of clinical learning environments for students is warranted given the shifting emphasis of contemporary nursing education; recognition of the importance of the clinical environment for learning and role development; and the need for managers to cultivate and monitor organisational culture to optimize learning.

\section{The importance of clinical learning environments}

The clinical learning environment is important not just for clinical skill development, but for students to also learn about the 'norms' of practice that is, processes in care delivery (Eraut, 2000). Ideally students join a team of clinicians to learn about professional practice (Egan and Jaye, 2009). There is an established body of knowledge about how students can be effectively integrated into these team environments (Twentyman et al., 2006; Henderson et al., 2006). Students value a sense of belonging (Levett-Jones et al., 2007). These environments are largely created via open communication channels within the clinical team and direct interactions with students during their placement (Andrews et al., 2006; Clarke et al., 2003).

Good communication between staff and students should involve reasoning and explore possibilities about practice (Orland-Barak and Wilhelem, 2005). Critical reasoning can be achieved when behavioural practices intrinsic to workplace learning encourage discussion and questioning around health care practices (Kell and Jones, 2007). Workplace learning behaviours are significant in how they influence and shape learning in the practice setting (Lave and Wenger, 1991).

Behaviours that facilitate learning about nursing practice and simultaneously encourage questioning in the workplace are of particular importance to eliminate traditional ritualistic approaches to patient care (Henderson et al., 2005). It is imperative that nursing practice is versatile and can respond to evidence to inform changes to practice rather than focus on a rigid structured delivery of tasks. 


\section{The history of learning in clinical nursing environments}

Contemporary requirements in clinical education are a significant departure from traditional approaches to the education of nurses. Historically nursing training required students attend to a work-load that was broken down into lists of tasks, each of which were allocated to a different nurse, and performed in a ritualistic fashion (Menzies, 1970).

This organisation and delegation of tasks observed by Menzies (1970) in her early seminal commissioned study to investigate nurse absenteeism was described as a strategy designed to reduce anxiety for nurses by limiting opportunities to better understand their patients' needs. Ultimately this approach minimised the capacity or ability of student nurses to exercise discretion and/or judgement (Menzies, 1970, p.29).

In response to these recognised limitations, nursing education subsequently attempted to recognise patients as individuals with needs to be addressed in a systematic problem-solving approach based on the use of evidence. A structured approach based on scientific principles was the basis of education to better understand patients' needs.

This 'nursing process' endemic throughout the profession in the western world seemed appropriate to enable students to learn and make sense of nursing (Walsh and Ford, 1994). However, the nursing process eventually reduced the capacity of nurses. Through its reductionist and fragmented approach the nursing process limited critical reflective thinking (Schon, 1983) and hindered independent decisionmaking.

\section{Contemporary learning environments}


In contemporary learning environments, students seek to become members of the clinical team during their clinical practical placement by acquiring the attributes of the professional nursing team with whom they interact (Melia, 1987, p.11). Students adopt survival strategies such as 'learning the rules' and 'getting the job done' (Melia, 1987). Students focus on 'fitting in' to practice environments rather than adopting a critical reflective stance.

More recently, similar experiences have been identified in Australia and the UK, where nurses strive to 'not rock the boat' so that they feel accepted into the clinical setting (Levett-Jones and Lathlean, 2009; Newton and McKenna, 2007). These behaviours do not foster questioning of practices or engagement with patients, nor encourage students to explore evidence around different patient management strategies (Newton, 2011).

Nursing has a strong history of prescribed behaviour. Contemporary approaches to teaching, identified by a significant move to tertiary education encourages nursing students to practice in a manner that challenges these stereotypes (Reid, 1994), and explore different forms of knowledge to address the diverse areas of their practice. Students are encouraged to critically analyse and respond to patients with individual needs.

Structured systematic staged learning can successfully embed fundamentals of good nursing practice that eventually become habitual (Benner, 1984). Expert nurses who have progressed through a trajectory of learning where routine skills have become automatic are able to recognise deviations to normal health and proactively structure health care arrangements that recognise difference and accordingly address the dignity needs of patients (Benner, 1984; Benner and Wrubel, 1989). 


\section{Desired characteristics of learning environments}

Ideally clinicians who partner with students in the learning environment offer opportunities to advance abstraction skills for professional practice, rather than delineate knowledge acquisition through transmission based experience (Kell and Jones, 2007).

Quality clinical learning occurs in environments that foster staff development and the advancement of skill acquisition in conjunction with independent thinking where nurses can initiate practice change based in the judicious use of evidence. Characteristics of learning environments are multifaceted. The literature identifies that learners need to be motivated, feel included, develop relationships with other team members, and feel safe to ask questions and explore practices (Senge, 2006, Henderson et al., 2010, Chan, 2001).

\section{An analysis of learning environments from contemporary studies}

Contemporary analyses of learning environments in nursing practice are not prolific. Descriptive studies of students' experiences are reasonably well published and while these provide insights their analysis is not comprehensive. However, a range of quantitative data can assist in providing information about trends. Parameters associated with positive learning environments for students have been articulated in the Clinical Learning Environment Inventory (CLEI). The CLEI measures students' perceptions of personalisation, involvement, task orientation, innovation, and individualisation that are pertinent to their psycho-social well being during the clinical practicum (Chan 2001, 2002, 2003).

\section{The Clinical Learning Environment Inventory}

The CLEl was developed by Chan $(2001,2002,2003)$ for use with student nurses to measure students' perceptions of the clinical learning environment. The CLEI consists of an Actual form which assesses the actual learning environment and the Preferred form which assesses what the student would ideally 
like in a learning environment. It identifies six factors associated with the psycho-social aspects of the clinical learning environment from the student's viewpoint.

The repetitive use of surveys enables learning environments to be monitored and examination of this data assists in better understanding learning environments. A CINAHL search using the search terms 'clinical learning environment inventory' and 'nursing' listed 56 manuscripts. Six papers from the 56 papers provided data that could be collected about actual Clinical Learning Environments as reported by students. These results that have emerged over the last decade add to the understanding of clinical learning contexts examined through the use of the CLEl. Table 1 details the outcomes of studies that have used the CLEl. The consistent feedback from students is discussed in the next section.

\section{An analysis of student feedback from Clinical Learning Environment Inventory}

Similarities in substantive findings across the studies indicate the usefulness in exploring similarities across different cultural contexts of practice in different countries. While the literature is limited, and much of it in Australian contexts, there are exemplars from across three countries. These provide insight into what could be argued 'typical' learning contexts.

Results from a range of studies using the CLEl indicate students are involved in the accomplishment of tasks (Smedley and Morey, 2009; Perli and Brugnolli, 2009; Henderson et al., 2006; Chan, 2004). Depending on the model of care used, students' perception of their recognition and involvement varied, however this was not as evident as task accomplishment. Regardless of model of care however, concepts such as innovation in clinical practice were not strong features of the clinical learning environment (Smedley and Morey, 2009; Chan and Ip, 2007; Midgley, 2006; Henderson et al., 2006). 
Table 1: Review of Studies Using Clinical Learning Environment Inventory (CLEI)

\begin{tabular}{|c|c|c|}
\hline Author & Sample & Findings \\
\hline Chan (2004) & $\begin{array}{l}\text { Second year BN students } \\
\text { (Australia) } \\
108 \text { CLEls (Chan, 2001) } \\
\text { returned (actual and preferred) }\end{array}$ & $\begin{array}{l}\text { Students perceived a need for improvement for all } \\
\text { sub-scales (difference between actual and } \\
\text { preferred). The effect sizes were large for all scales } \\
\text { except Involvement with a medium effect size. } \\
\text { Students' level of satisfaction was found to be } \\
\text { associated will all five scales. Students who } \\
\text { perceived their placements as greatly positive place } \\
\text { high expectation on Task Orientation. } \\
\text { Personalisation scored the highest mean in both } \\
\text { actual and preferred survey results and Innovation } \\
\text { the lowest }\end{array}$ \\
\hline $\begin{array}{l}\text { Henderson et al } \\
(2006)\end{array}$ & $\begin{array}{l}\text { First, second and third year BN } \\
\text { students (Australia) } \\
389 \text { CLEls (Chan, 2001) Actual } \\
\text { only }\end{array}$ & $\begin{array}{l}\text { Satisfaction and Task orientation were the highest } \\
\text { rated sub-scales by students with Individualisation } \\
\text { and Student involvement the lowest. }\end{array}$ \\
\hline Midgley (2006) & $\begin{array}{l}\text { Second year BN student (UK) } \\
67 \text { CLEls (Chan, 2001) returned } \\
\text { (actual and preferred) }\end{array}$ & $\begin{array}{l}\text { Satisfaction and personalization were perceived as } \\
\text { the most important sub-scales. Students would } \\
\text { prefer the actual environment to have higher levels of } \\
\text { individualisation, teaching innovation, student } \\
\text { involvement, personalization and task orientation. } \\
\text { The greatest difference between actual and preferred } \\
\text { environment was in the innovation sub-scale }\end{array}$ \\
\hline $\begin{array}{l}\text { Chan and Ip } \\
(2007)\end{array}$ & $\begin{array}{l}\text { All students in a BN (Hong } \\
\text { Kong) } \\
281 \text { CLEls (Chan, 2001) } \\
\text { returned (actual) and } 243 \\
\text { (preferred) }\end{array}$ & $\begin{array}{l}\text { Personalization scored the highest mean in both } \\
\text { actual and preferred surveys. Teaching innovation } \\
\text { scored the lowest mean in actual and preferred } \\
\text { versions. } \\
\text { Students preferred an environment at higher levels } \\
\text { that those perceived in the actual experience. }\end{array}$ \\
\hline $\begin{array}{l}\text { Perli and } \\
\text { Brugnolli (2009) }\end{array}$ & $\begin{array}{l}\text { First, second and third year BN } \\
\text { students (Italy) } \\
232 \text { CLEls (Chan, 2001) } \\
\text { returned (actual and preferred) }\end{array}$ & $\begin{array}{l}\text { Little difference between actual and preferred scores } \\
\text { in each sub-scale. Personalisation }(M=4.08) \text {, } \\
\text { Involvement }(M=4.09) \text {, Satisfaction }(M=4.14) \text { the } \\
\text { sub-scales ranked highest (actual). Individualisation } \\
\text { had the lowest mean score }(M=3.19)\end{array}$ \\
\hline $\begin{array}{l}\text { Smedley and } \\
\text { Morey (2009) }\end{array}$ & $\begin{array}{l}\text { Senior Australian BN students } \\
55 \text { CLEls (Chan, 2001) returned } \\
\text { (actual) and } 38 \text { (preferred) }\end{array}$ & $\begin{array}{l}\text { Students perceived a need for improvement for all } \\
\text { sub-scales (difference between actual and preferred) } \\
\text { Task orientation, teacher innovation and } \\
\text { individualisation scored lowest on actual experience } \\
\text { with teacher innovation the lowest. Task orientation } \\
\text { was the strongest predictor of student satisfaction } \\
\text { and students perceived task orientation as a } \\
\text { precursor to student involvement. }\end{array}$ \\
\hline
\end{tabular}




\section{Discussion}

The relatively high mean scores for the scales related to task accomplishment universally across studies using the CLEl indicate nursing cultures focused on performing tasks. Health care settings positively contribute to learning that involves the completion of work (Maben, Latter, Macleod Clark 2006). Nursing has a strong tradition around apprentice type learning, that is, formulaic learning of skills (Melia, 1987); and the present exploration drawing on the availability of quantitative findings indicate that these origins still prevail. There is strength in such training because students have a firm grounding in tasks and so can perform tasks 'automatically' while they communicate and focus on other patient needs.

Survey responses also indicated a sense of affiliation within the learning environments. This included recognition by students that they were included, that is, sharing of tasks, activities or skills and in particular, students fitting into the ward work (Levett-Jones and Lathlean, 2009; Newton and McKenna, 2007). Inclusion in the work based team is a strong predictor of satisfaction in the work culture (Chan, 2004; Smedley and Morey, 2009). Consistently, a sense of acceptance and belonging is important for students (Levett-Jones et al. 2007). Students work towards being identified with these environments and hence, readily contribute to the completion of tasks.

Individualisation was not as strong as other parameters for all the studies that were able to be sourced (Smedley and Morey, 2009; Perlie and Brugnolli, 2009; Henderson et al., 2006). As such, students indicate that opportunities to interact with staff on an individual basis during the clinical placement were not nearly as strong as their engagement in accomplishing tasks. While task accomplishment and affiliation that assists this is important for learning there is limited evidence that students feel they can influence, that is, question or make suggestions about changes to practice. Contemporary health care contexts need to foster inquiry in practice to ensure contemporary quality care. 
From the literature reviewed students did not feel that they could easily influence, that is, initiate dialogue around rationale for practices. Learning environments are perceived by students to be inclusive and effective in maintaining continuity in present practice but not readily open to innovation. The possible disinclination towards innovation may be indicative of staff teaching students through a knowledge transmission rather than facilitating students to explore possibilities in the practice situation (Kell and Jones, 2007).

\section{Implications for practice}

Contemporary health care environments require that staff invite questions from students and respond to their comments if quality health care is to be maintained. The exploration of the learning contexts lends itself to two courses of action - one short term and in the longer term to work towards the goal of quality patient care.

In the short term, areas of practice ideally should have nurse specialists or champions who are knowledgeable about the specific health practices and also motivated to explore how relevant evidence can be readily implemented into practice (Winch et al., 2005). These staff can then formulate actions and tasks that can be integrated into practice as it is recognised that staff are largely compliant with attending to tasks that have become routine practice.

In the longer term leadership practices are needed to transform the dominant value of 'set routines' and task orientation to a culture that encourages seeking new ways to improve practice and care. In this way clinical leadership needs to focus on and encourage reflective practice as it has been shown to both improve client care and nurses role satisfaction (Flanagan, 2009). 


\section{Conclusion}

Monitoring the learning environment from the perspective of staff and students can inform structures, processes, and practices that are effective or need to be developed to foster learning within their clinical contexts. Nursing has a strong task focused culture and short term strategies that capitalise on these traditional strengths can be used in the interim while ward culture develops so that nurses are facilitated to question and explore changed practice based in evidence. 


\section{References}

Andrews, G.J., Brodie, D.A., Andrews, J.P., Hillan, E., Thomas, B.G., Wong, J., Rixon, L. (2006) Professional roles and communications in clinical placements: A qualitative study of nursing students' perceptions and some models for practice. International Journal of Nursing Studies 43, 861-874.

Benner P. (1984) From Novice to Expert. Menlo Park: Addison Wesley.

Benner P., Wrubel J. (1989) The primacy of caring. Menlo Park: Addison Wesley.

Chan D. (2001) Development of an innovative tool to assess hospital learning environments. Nurse Education Today, 21, $624-631$.

Chan, D. (2002) Development of the clinical learning environment inventory: using the theoretical framework of learning environment studies to assess nursing students' perceptions of the hospital as a learning environment. Journal of Nursing Education. 41(2): 69-75.

Chan, D. (2003) Validation of the clinical learning environment inventory. Western Journal of Nursing Research, 25(5):519-532.

Chan, D. (2004). The relationship between student learning outcomes from their clinical placement and their perceptions of the social climate of the clinical learning environment. Contemporary Nurse, 17, $149-158$.

Chan, D \& Ip W. (2007) Perception of hospital learning environment: A survey of Hong kong nursing students. Nurse Education Today, 27, 677 - 684.

Clarke, C., Gibb, C., Ramprogus V. (2003) Clinical learning environments: an evaluation of an innovative role to support pre-registration nursing placements. Learning in Health and Social Care, 2(2): 105-115.

Egan, T., Jaye, C. (2009) Communities of clinical practice: the social organization of clinical learning. Health: An Interdisciplinary Journal for the Social Study of Health, IIIness \& Medicine 13(1);107125.

Eraut, M. (2000) Non-formal learning and tacit knowledge in professional work. British Journal of Educational Psychology, 70, 113-36.

Flanagan, J. (2009) Patient and nurse experiences of theory-based care. Nursing Science Quarterly, $22,160-172$. 
Henderson A., Heel A., Twentyman M. (2007) Enabling student placement through strategic partnerships between a health-care organization and tertiary institutions. Journal of Nursing Management 15: 91-96.

Henderson A., Winch S., Grugan C., Henney R., McCoy R. (2005) 'Working from the inside': An infrastructure for the continuing development of nurses' professional clinical practice. Journal of Nursing Management, 13: 106-110.

Henderson A, Winch S, Heel A. (2006) Partner, learn, progress: a conceptual model for continuous clinical education, Nurse Education Today, 26: 104-109.

Kell C., Jones L. (2007) Mapping placement educators' conceptions of teaching, Physiotherapy, 93, 273-282.

Lave, J., Wenger E. (1991) Situated learning: legitimate peripheral participation. Cambridge: Cambridge University Press.

Levett-Jones, T., Lathlean, J., Maguire, J., McMillan, M. (2007) Belongingness: a critique of the concept and implications for nursing education. Nurse Education Today 27 (3), 210-218.

Melia, K.M. (1987) Learning and Working: The occupational socialisation of nurses. London: Tavistock.

Menzies, I. (1970) The functioning of social systems as a defence against anxiety. Tavistock Pamphlet No.5.

Midgley, K. (2006) Pre-registration student nurses perception of the hospital-learning environment during clinical placements. Nurse Education Today, 26, 338-345.

Newton, J.M.(2011) Chapter Seven: Reflective learning groups for student nurses

In Billett S., Henderson A. (Eds) Developing learning professionals: Integrating experiences in university and practice settings

Newton, J. M., McKenna, L., 2007. The transitional journey through the graduate year: A focus group study. International Journal of Nursing Studies 44 (7), 1231-1237

Orland-Barack L., Wilhelem D., 2005. Novices in clinical practice settings: Student nurses stories of learning the practice of nursing. Nurse Education Today 25, 455-464.

Papp I, Markkanen M, von Bonsdorff M. (2003) Clinical environment as a learning environment: student nurses' perceptions concerning clinical learning experiences. Nurse Education Today 23: 262268. 
Perli, S. \& Brugnolli, A. (2009) Italian nursing students' perception of their clinical learning environment as measured with the CLEl tool. Nurse Education Today, 29, 886-890.

Reid J.C.(1994) Nursing Education in Australian Universities. Report of the National review of nurse Education in the Higher Education Sector- 1994 and beyond. Canberra: Australian Government Publishing Service

Schon D. (1983) The reflective practitioner. New York: Basic Books.

Smedley, A. \& Morey, P. (2010) Improving learning in the clinical nursing environment: perceptions of senior Australian bachelor of nursing students. Journal of Research in Nursing, 15, 75-88.

Twentyman M., Eaton E, Henderson A. (2006) Enhancing support for nursing students in the clinical setting, Nursing Times, 102(14): 35-37.

Walsh M \& Ford P. (1994) New rituals for old: Nursing through the looking glass. Oxford: ButterworthHeinemann.

Winch S., Henderson A. and Creedy D. (2005) Read, Think, Do: a method for fitting research evidence into practice. Journal of Advanced Nursing, 50(1): 20-26. 